Füße sind mir eingeschlafen." "Ebendort in einer Erzählung S. 282. Bei den Verba des Denkens kann diese Konstruktion ebenfalls angewendet werden.

München.

E. Kieckers.

\title{
Zum passiven Imperativ im Lateinischen.
}

Sommer bemerkt Handb. der lat. Laut- und Formenlehre ${ }^{2} 515$, daß ein laudare 'werde gelobt' und ähnliche Formen in den zweiten Personen des Passivs im Lateinischen nicht bestanden hätten, daß es vielmehr nur deponential-mediale Formen dieser Art gegeben habe, und verweist dafür auf H. J. Müller Ztschr. f. d. Gymnasialwesen 39, 436, Fußnote.

Diese Behauptung läßt sich so ausnahmslos nicht aufrecht erhalten. Ich entsinne mich aus meiner Lektüre der Stelle: fallax Tantaleo corripere ore liquor Prop. eleg. 5, 11, 24. Wörtlich übersetzt heißt es: 'Trügerisches Wasser, werde vom Munde des Tantalus ergriffen". Wir können natürlich freier übersetzen: 'laß dich trinken', aber der Lateiner kann eine solche Wendung doch nur rein passivisch, nicht medial aufgefaßt haben. Corripere indikativisch zu fassen, verbietet der Zusammenhang. Unmittelbar vorher heißt es im Conjunctivus optativus Sisyphe, mole vaces, taceant Ixionis orbes, und unmittelbar nachher ebenso Cerberus et nullas hodie petat improbus umbras, Et iaceat tacita lapsa catena sera. Vers 24 kann deshalb nur imperativisch verstanden werden.

München.

E. Kieckers. 